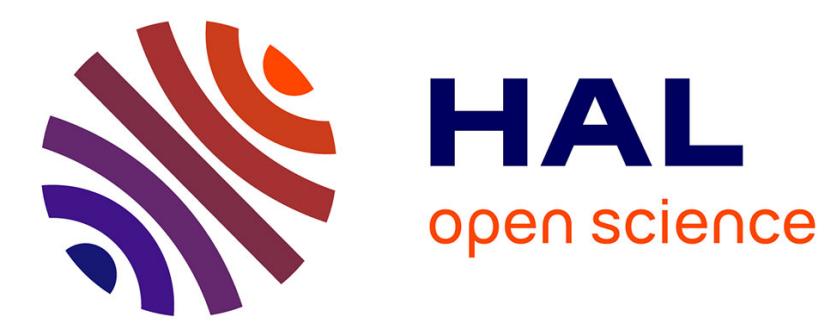

\title{
Regionalization of outputs of two crop protection models using geostatistical tools and NOAA-AVHRR images
}

\author{
Karem Chokmani, Alain A. Viau, Gaétan Bourgeois
}

\section{To cite this version:}

Karem Chokmani, Alain A. Viau, Gaétan Bourgeois. Regionalization of outputs of two crop protection models using geostatistical tools and NOAA-AVHRR images. Agronomy for Sustainable Development, 2005, 25 (1), pp.79-92. hal-00886251

\section{HAL Id: hal-00886251 https://hal.science/hal-00886251}

Submitted on 1 Jan 2005

HAL is a multi-disciplinary open access archive for the deposit and dissemination of scientific research documents, whether they are published or not. The documents may come from teaching and research institutions in France or abroad, or from public or private research centers.
L'archive ouverte pluridisciplinaire HAL, est destinée au dépôt et à la diffusion de documents scientifiques de niveau recherche, publiés ou non, émanant des établissements d'enseignement et de recherche français ou étrangers, des laboratoires publics ou privés. 


\title{
Regionalization of outputs of two crop protection models using geostatistical tools and NOAA-AVHRR images
}

\author{
Karem CHOKMANI ${ }^{a *}$, Alain A. VIAU ${ }^{\mathrm{b}}$, Gaétan BOURGEOIS ${ }^{\mathrm{c}}$ \\ a INRS-ETE, 490 rue de la Couronne, Québec (Qc), Canada, G1K 9A9 \\ ${ }^{\mathrm{b}}$ Geomatics Research Centre, Casault Building, Laval University, Quebec City, Qc, Canada G1K 7P4 \\ ${ }^{\mathrm{c}}$ Agriculture and Agri-Food Canada, Horticulture Research and Development Centre, 430 Blvd. Gouin, Saint-Jean-sur-Richelieu, Qc, Canada J3B 3E6
}

(Received 26 January 2003; accepted 7 October 2004)

\begin{abstract}
Crop protection forecasting models currently use meteorological data observed at stations to produce pest infection and development indices. The indices are then extrapolated to the regional level by assuming that the weather conditions at the stations are similar to those in neighbouring fields in the region, which is not necessarily the case. Hence, this has a significant impact on the quality of the recommendations and diagnoses based on computerized plant protection models. The regionalization of model outputs between the stations comprising the weather network, using geostatistical techniques such as cokriging in conjunction with satellite data, is a worthwhile approach for addressing this need. The objective of this study is to develop and apply a methodology for regionalization of infection indices produced by two crop protection models contained in the CIPRA (Computer Centre for Agricultural Pest Forecasting) system, using geostatistical tools and NOAAAVHRR images. This approach will help enhance our crop pest management and forecasting capabilities while optimizing the use of pest control products in vegetable crops in Quebec. To achieve our objective, a cokriging method was applied to regionalize the model outputs using air temperature and relative humidity estimated from NOAA-AVHRR images. The results were then validated against a regionalization approach using ordinary kriging and two conventional interpolation techniques.
\end{abstract}

crop protection / remote sensing / NOAA-AVHRR / geostatistics / cokriging

\section{INTRODUCTION}

The CIPRA (Computer Centre for Agricultural Pest Forecasting) system developed by Bourgeois et al. [2] is a collection of forecasting models in a common computer infrastructure (20 insect pest models and 10 disease models for 10 different crops). These models exploit the stochastic relationships between the pest and the local weather conditions to produce pest development indices. They are easy to use because they require only standard meteorological data. With the establishment of a computerized central network by Environment Canada's Atmospheric Environment Service, providing access to meteorological data from a number of automatic stations, CIPRA has become one of the first operational decision-making support systems for crop protection in Canada $[1,9]$.

Integrated pest management programs have often stressed the importance of taking the spatial dimension of pests attacks into account in order to optimize action plans and understand their ecology and epidemiology [12, 27, 31]. Given the heterogeneous nature of the habitat and of disease development conditions, a realistic modelling approach must take the spatial variability of the information into account. Despite this concept of spatial variability, pest control programs continue to rely on estimation of a mean value of the risk, occurrence or incidence of the pest in the field for the purpose of initiating treatments, for the entire field or entire region concerned.

At the present time, CIPRA crop protection forecasting models are applied locally. These models use meteorological data observed at stations to produce pest infection and development indices. The indices are then extrapolated to the areas outside the stations by assuming that the weather conditions at the stations are similar to those in neighbouring fields, which is not necessarily the case. In fact, the information measured at the station is valid only for a certain radius around the station. Furthermore, the density and spatial distribution of the weather stations are not optimal [23, 28, 29]. Similarly, pest monitoring activities are limited to observing the presence and/or incidence of pests at a finite number of locations in a field or for the region concerned. The results of this sampling, which are intended to be representative of pest development, are then extrapolated to the entire field or entire region concerned.

Hence, the spatial dimension is taken into consideration only implicitly in the development of warnings and recommendations, even though they are regional in scope. The quality of the recommendations and diagnoses based on forecasting models and pest monitoring results is therefore significantly affected

* Corresponding author: karem_chokmani@inrs-ete.uquebec.ca 
Table I. Main characteristics of the two studied models.

\begin{tabular}{|c|c|c|c|c|}
\hline Model & Time interval & Inputs & Outputs & Action threshold \\
\hline Leaf blight of onion & Hourly & $\begin{array}{c}\text { Temperature } \\
\text { Relative humidity }\end{array}$ & $\begin{array}{c}\text { Sporulation index } \\
\text { (ranges from } 0 \text { to 100) }\end{array}$ & $\begin{array}{c}50 \text { (moderate risk) } \\
\text { OR } \\
80 \text { (high risk) }\end{array}$ \\
\hline Carrot weevil & Daily & $\begin{array}{l}\text { Max. temperature } \\
\text { Min. temperature }\end{array}$ & Degree days & 202 DD ( $10 \%$ of oviposition) \\
\hline
\end{tabular}

because of this fragmentary view of pest infestations despite their regional scope. Intervention decisions are made on the basis of subjective knowledge about the distribution of the disease. The development of more objective procedures based on the spatial distribution of pest infestations could support the decision-making process and consequently lead to more accurate and more justifiable decisions [30].

Various statistical techniques can be used to study the spatial distribution of pests and to produce risk/occurrence/incidence maps. Legendre and Fortin [20], Campbell and Madden [4], Legendre [19] and Real and McElhany [25] have provided an exhaustive review of the methods used for these purposes. However, in order for a technique to be appropriate, it must take into account the actual location of the samples and their relationship with the neighbourhood [19]. Otherwise, very useful information on the spatial structure of the variable in question is lost. Geostatistics are better adapted for this purpose, since they incorporate spatial interdependence in their analysis and use it to estimate the variable where it is not observed [11, 19, 26].

The rules of occurrence and spatial distribution of pests are governed by the biophysical structure of their habitat as well as by the presence or absence of target crops and their stage of development. The use of remote sensing data in plant protection to characterize the environmental context in which pests and their vectors develop for the purpose of assessing their risk/ incidence/occurrence has been extensively documented $[3,15$, $17,22]$. The interpretation of these data can provide indications about ground cover, condition of the vegetation, as well as surface and atmospheric conditions, providing a low-cost tool for monitoring the development of pests and their vectors. In fact, because of the time, effort and money involved in monitoring pests and their hosts, identifying environmental variables that are easily measurable by remote sensing could enhance our ability to assess the risk of pest infestations over large areas as well as on small plots.

The combined use of remote sensing data and geostatistical techniques is a promising tool for studying the spatial characteristics of crop diseases as well as insect pest population dynamics on a regional scale. In addition, this approach can help enhance our crop pest management and forecasting capabilities while at the same time optimizing the use of pest control products. However, the use of such an approach remains limited.

The main objective of this study is to develop and apply a methodology for regionalization of risk indices produced by two models contained in the CIPRA system by using geostatistical tools and NOAA-AVHRR images. Data from the NOAA-AVHRR sensor were used as auxiliary variables to regionalize the outputs of the two models with a cokriging approach. The results obtained were then validated against an approach using ordinary kriging and two conventional interpolation techniques, namely the nearest neighbour method and the inverse distance weighted average method.

\section{MATERIALS AND METHODS}

\subsection{Crop protection models}

Because of the large number of models within the CIPRA system, we limited our analysis to one fungal disease model, namely leaf blight of onion (Botrytis squamosa (J.C. Walker)), and one insect model, namely carrot weevil (Listronotus oregonensis (Le Conte)). These models were chosen because of the economic importance of the crops concerned, the magnitude of potential damage caused by these pests and, particularly, because they are fairly representative of all the CIPRA models. Table I provides a summary of the main characteristics of these two models.

A preliminary sensitivity analysis of the two models with respect to fluctuations in their input meteorological variables permitted to identify the variables with the most significant impact on their performance [8]. The leaf blight of onion model is essentially sensitive to fluctuations in relative humidity. The weevil model is more sensitive to maximum temperature than to minimum temperature. Efforts to extract variables from NOAA-AVHRR images were therefore concentrated on air temperature and air humidity $[6,7]$.

\subsection{Territory under study}

The region under study is located in the southwestern Quebec, between longitude $72^{\circ}-75^{\circ}$ West and latitude $45^{\circ}-46^{\circ} 30^{\prime}$ North (Fig. 1). The region is part of the larger St. Lawrence River system. The topography in this area is relatively flat with slight differences in level near the St. Lawrence River and its tributaries. In general, the elevation ranges from 15 to $75 \mathrm{~m}$ and rarely exceeds $150 \mathrm{~m}$. The territory is bounded to the north by the mountainous region of the Laurentian Highlands and to the south by the Eastern Quebec Uplands. The climate is characterized by warm summers and cold, snowy winters. The mean summer temperature is $16.5^{\circ} \mathrm{C}$. Mean annual precipitation is 800 to $1000 \mathrm{~mm}$. The territory under study is primarily agricultural.

\subsection{Data}

Hourly data from 26 automatic weather stations located in the study area (Tab. II, Fig. 1) were used to calculate the outputs 


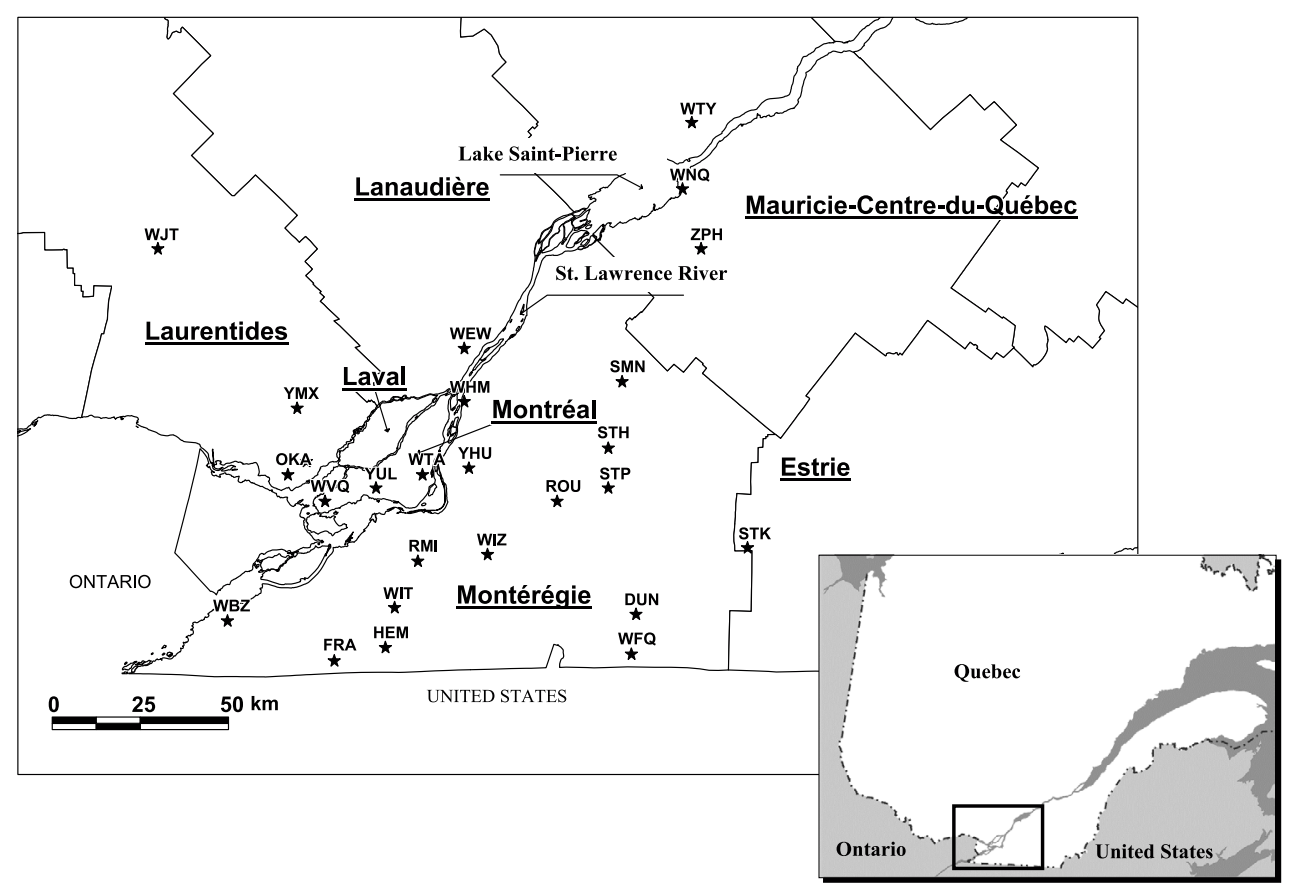

Figure 1. Location of the territory and of the used meteorological stations.

Table II. Automatic weather stations used.

\begin{tabular}{|c|c|c|c|c|}
\hline Station name & Organization & ${ }^{\circ}$ Longitude & ${ }^{\circ}$ Latitude & Elevation (m) \\
\hline L'Assomption & $\mathrm{AES}^{\mathrm{a}}$ & -73.43 & 45.82 & 21 \\
\hline Frelighsburg ${ }^{\dagger}$ & AES & -72.83 & 45.05 & 152 \\
\hline Sainte-Clotilde & AES & -73.68 & 45.13 & 52 \\
\hline L'Acadie & AES & -73.35 & 45.30 & 45 \\
\hline Nicolet & AES & -72.65 & 46.22 & 8 \\
\hline Sainte-Anne-de-Bellevue & AES & -73.93 & 45.43 & 39 \\
\hline Saint-Anicet & AES & -74.28 & 45.12 & 49 \\
\hline Saint-Jovite & AES & -74.53 & 46.07 & 239 \\
\hline Varennes & AES & -73.43 & 45.68 & - \\
\hline McTavish & AES & -73.58 & 45.50 & 72 \\
\hline Trois-Rivières & AES & -72.62 & 46.38 & 55 \\
\hline Mirabel & AES & -74.03 & 45.67 & 82 \\
\hline Saint-Hubert & AES & -73.42 & 45.52 & 27 \\
\hline Dorval & AES & -73.75 & 45.47 & 31 \\
\hline Oka & MAPAQ $^{\mathrm{b}}$ & -74.07 & 45.50 & - \\
\hline Rougemont & MAPAQ & -73.10 & 45.43 & 40 \\
\hline Dunham & MAPAQ & -72.82 & 45.15 & 121 \\
\hline Franklin & MAPAQ & -73.90 & 45.03 & 145 \\
\hline Hemmingford & MAPAQ & -73.72 & 45.07 & 61 \\
\hline Saint-Hyacinthe & MAPAQ & -72.92 & 45.57 & 33 \\
\hline Saint-Joseph-du-Lac & MAPAQ & -74.00 & 45.53 & - \\
\hline Saint-Paul-d'Abbotsford & MAPAQ & -72.92 & 45.47 & 63 \\
\hline Saint-Rémi & $\mathrm{MEF}^{\mathrm{c}}$ & -73.60 & 45.28 & 53 \\
\hline Saint-Simon & MEF & -72.87 & 45.73 & - \\
\hline Saint-Zéphirin & MEF & -72.58 & 46.07 & 52 \\
\hline Stukely & MEF & -72.42 & 45.32 & - \\
\hline
\end{tabular}

${ }^{a}$ Atmospheric Environment Service, Environment Canada; ${ }^{b}$ Quebec Department of Agriculture, Fisheries and Food; ${ }^{c}$ Quebec Department of the Environment and Wildlife. 
of the models in question, over the 1997 agricultural season (April to September).

The satellite images used were acquired by the AVHRR sensor on board the NOAA-12 and NOAA-14 satellites [10]. The images cover the first 10-day period of the months of June and July 1997. Originally, we had at least three images per day, for every day within these two periods: one in the early morning (local time), one in the early afternoon and one in the late afternoon/early evening. After a visual selection, only the images with minimal cloud cover were retained. On the days of June $1,4,7,9$ and 10 and July 1, 2, 3, 4, 5, 8 and 9 , the cloud cover was very heavy above the study area, rendering the corresponding images unusable. The remaining images were used to calculate the satellite air temperature and air humidity. The details concerning extraction of the satellite variables are described in Chokmani [6] and Chokmani and Viau [7].

The early afternoon air temperature images were chosen as auxiliary variable for the purpose of regionalization of the results of the weevil model (primary variable). In fact, the temperature calculated from the images taken in the early afternoon provides a good estimate of the maximum daily temperature $[24,29]$. On the other hand, since the periods of high humidity, conducive to outbreaks of fungal diseases, occur in the early morning or at dusk [14], the morning images of relative humidity were chosen as auxiliary variable for the purpose of regionalization of the results of the Botrytis model.

Moreover, the satellite images must have a sufficiently large spatial coverage in order to provide a sufficient number of points where the primary variable and the auxiliary variable are available simultaneously. Given this constraint, in addition to those relating to the availability of outputs on the image acquisition dates, the air temperature images chosen for the purpose of regionalization of the model outputs were: June 3, 1997 (154th Julian day) at 2:00 pm, June 5 (156th Julian day) at 2:00 pm and June 8 (159th Julian day) at 1:00 pm. Similarly, the air humidity images of July 6 (187th Julian day) and July 10 (191st Julian day) at 8:00 am were used.

The simulation results of the two models were calculated for the satellite image acquisition dates and times. On the following acquisition dates, the leaf blight of onion model (Botrytis) produced non-null sporulation indices exceeding the moderate risk threshold for several stations and the high risk threshold for certain dates: the 153rd Julian day (June 2) at 7:00 am and the 187th (July 6) and 191st (July 10) at 8:00 am. For the other dates corresponding to the morning images, the sporulation index values were virtually null.

For the insect model (weevil), all the dates were potentially useable. The only limiting factor was the availability of air temperature images acquired at mid-day with light cloud cover. Moreover, it should be pointed out that the action threshold of the weevil model 202 DD was reached on the 156th Julian day (June 5), at most stations.

\subsection{Interpolation methods}

Given the extensive and detailed literature on the various interpolation procedures [13, 16, 18, 21, 26], we will provide here only a brief description of the various approaches used.
For the various interpolation methods studied (kriging, cokriging, inverse distance and nearest neighbour), the value of the variable $Z$ at the unsampled point $x_{0}, Z *\left(x_{0}\right)$ (in this case, the model output) is estimated using a linear combination of the $Z\left(x_{i}\right)$ values observed in the neighbourhood of the point (outputs calculated at the weather stations):

$$
Z^{*}\left(x_{0}\right)=\sum_{i=1}^{n} w_{i} Z\left(x_{i}\right)
$$

where, $w_{i}$ are the weighting coefficients assigned to each $Z\left(x_{i}\right)$ value and $n$ is the number of nearest observed points used for estimation.

Kriging calculates the weighting coefficients $w_{i}$ by estimating the structure of the spatial distribution of the variable using the structure function (covariogram, variogram, correlogram, etc.). This structure function expresses the covariance (variance) between the observed points as a function of the distance between them. It describes the degree and form of spatial autocorrelation of the variable in question. The observed structure function cannot be used as is in calculating the $w_{i}$, since it represents a spatially discrete measurement of autocorrelation. A theoretical model, chosen from among a limited set of authorized models [16], is therefore fitted to this observed structure function. The quality of the estimation depends on the choice of model. It must be based on actual knowledge of the phenomenon rather than solely on the accuracy of the mathematical fitting. Once the spatial autocorrelation structure is modelled, the model is used to calculate the coefficients $w_{i}$.

Cokriging is simply the extension of kriging to more than one variable by taking advantage of the spatial correlation that exists between the primary variable and the auxiliary variable or variables. In our case, the primary variable is represented by the outputs of the models in question. Each model has only one auxiliary variable associated with it. This is the satellite variable: air temperature or relative humidity, depending on the model. Here again, the estimation is a linear combination of the primary variable and the auxiliary variable:

$$
Z^{*}\left(x_{0}\right)=\sum_{i=1}^{n} w_{i} Z\left(x_{i}\right)+\sum_{j=1}^{m} v_{j} U\left(x_{j}\right)
$$

where $w_{i}$ are the weighting coefficients assigned to each value of the primary variable $Z\left(x_{i}\right), n$ is the number of nearest observed points used for estimation, $v_{i}$ are the weighting coefficients assigned to each value of the auxiliary variable $U\left(x_{j}\right)$ and $m$ is the number of points where the auxiliary variable is observed in the neighbourhood of the point being estimated.

The cokriging system is also subject to the conditions of universality and minimum variance. Here, the condition of universality means that the sum of $w_{i}$ and $v_{i}$ must be equal to 1 . The most commonly used method for attaining this objective is to divide the condition of universality into two and ensure that the sum of the $w_{i}$ equals 1 , on the one hand, and that the sum of the $v_{i}$ equals 0 , on the other. There are other possible approaches for ensuring the condition of universality, for example using a single condition where the sum of the $w_{i}$ and $v_{i}$ together is equal to 1 .

Solving the equations of the cokriging system in order to obtain weighting coefficients involves the simultaneous use of simple and cross models of the structure function of the main and auxiliary variables. The cross structure function describes 
the spatial interdependence between the primary variable and the auxiliary variable. The cokriging system requires the existence of at least one neighbouring point where the main and auxiliary variables are observed simultaneously.

Where the variable exhibits anisotropy, cokriging makes it possible to perform the directional analysis (in a specific direction) of the spatial autocorrelation. However, given the limited size of the sample used in this study (26 stations), the anisotropy aspects were not studied. Only the covariograms and omnidirectional variograms were calculated.

For the inverse distance method, the weighting coefficients are calculated using the following weighting function:

$$
w_{i}=\frac{1 / d_{i}^{p}}{\sum_{i=1}^{n} 1 / d_{i}^{p}}
$$

where $d_{i}$ is the distance between the point to be estimated and the observed neighbouring point and $p$ is an exponent parameter. This parameter is chosen arbitrarily. It has been demonstrated that the choice of exponent parameter significantly affects the quality of the estimation. A value of 2 is commonly used [16] and this is the value we chose for estimation by the inverse distance method. Moreover, the distance weighting function (Eq. (3)) guarantees an unbiased estimation (condition of universality), since the sum of the weighting coefficients is equal to 1 . However, the inverse distance method does not include any provision for producing an optimal estimation for which the estimation error is minimal.

The nearest neighbour method simply involves selecting the observed value closest to the point being estimated as the estimated value. At present, this technique is commonly used by crop protection officials (intuitively) to interpret model results. In fact, in order to monitor the development of pests and initiate an appropriate response, crop protection officials use the results of forecasting models that were calculated using data from the meteorological station closest to the field or region concerned. In a manner of speaking, the nearest neighbour method is a variant of the inverse distance method. When the parameter $p$ tends toward infinity, the weighting function tends to transfer all the weight to the value of the nearest neighbour.

Except for the nearest neighbour method, all the other interpolation techniques used require the definition of an optimal neighbourhood structure. This structure defines the neighbouring points to be included in the estimation, for which weighting coefficients are calculated according to the technique used. The performance of the interpolation technique is greatly affected by the quality and number of neighbouring observations used for estimation. In our case, where the anisotropy aspects were not studied, the neighbourhood structure was in the shape of a circle whose radius was determined using the spatial autocorrelation structure described by the structure function. In order to minimize the possible redundancy effect in the observations chosen, the neighbourhood search circle was subdivided into several sectors, each containing an optimal number of points. It should be pointed out that in order to facilitate comparison of interpolation methods, the same neighbourhood structure was used for each variable by the various interpolation techniques.

\subsection{Validation}

The various interpolation methods were compared using crossvalidation. During this process, the interpolation method was tested at the points already sampled (the 26 weather stations). The value observed at a given point was temporarily removed from the set of known points. The value at this location was then estimated using the values of the remaining sampling points. The estimated value was then compared to the true value initially removed from the sample. This operation was repeated, one by one, for all the sampled points.

\section{RESULTS AND DISCUSSION}

\subsection{Leaf blight of onion (Botrytis) model}

The 187th and 191st Julian days are the two dates for which the leaf blight of onion model produced useable results. For these two dates, the sporulation index and relative humidity values were observed simultaneously at 13 and 8 stations out of 26 , respectively. These observation points were used to study the spatial interdependence between the two variables. The coefficient of determination demonstrates the a priori existence of a fairly strong linear dependence between the model output and the satellite variable. The coefficients of determination between these two variables for the two dates were 0.84 and 0.70 , respectively.

Both dates were associated with morning images characterized by light cloud cover, allowing the satellite relative humidity images to be used as auxiliary variable. The risk of infection was high on the days preceding these two dates, when there was heavy cloud cover. These days were characterized by conditions conducive to the development of fungal diseases (high temperature and humidity). Since this model takes into consideration the conditions of the last 72 hours [8], the high-risk periods produced by the Botrytis model extend beyond these characteristic days. Hence, the sporulation events continue beyond the days considered and this makes it possible to use the satellite imagery for regionalization of the model's outputs.

The simple and cross variograms of the two variables for the two dates were calculated with a distance interval (lag) of $15 \mathrm{~km}$ and a distance tolerance of $50 \%$. Figure 2 shows only the variograms relating to the 187 th Julian day.

The Botrytis sporulation index exhibits an obvious spatial structure. The observed simple variograms (Fig. 2A) begin with a low variance at very short distances. Then, the variance increases quickly with distance. Around $75 \mathrm{~km}$, rate of increase slows down. Past this distance, it becomes more or less chaotic. This could be explained by the decrease in the number of pairs of stations used in the calculations. In fact, past this distance, the number of pairs drops quickly from about 40 to about 20 .

Satellite relative humidity also exhibits a very obvious spatial structure (Fig. 2C). However, a discontinuity at the origin must be noted (a non-null variance at very short distances). This may be attributable to the variable estimation error. It will be recalled that satellite relative humidity is the result of a nonlinear combination of satellite air temperature and precipitable water, and these data are in turn estimated with a certain degree 

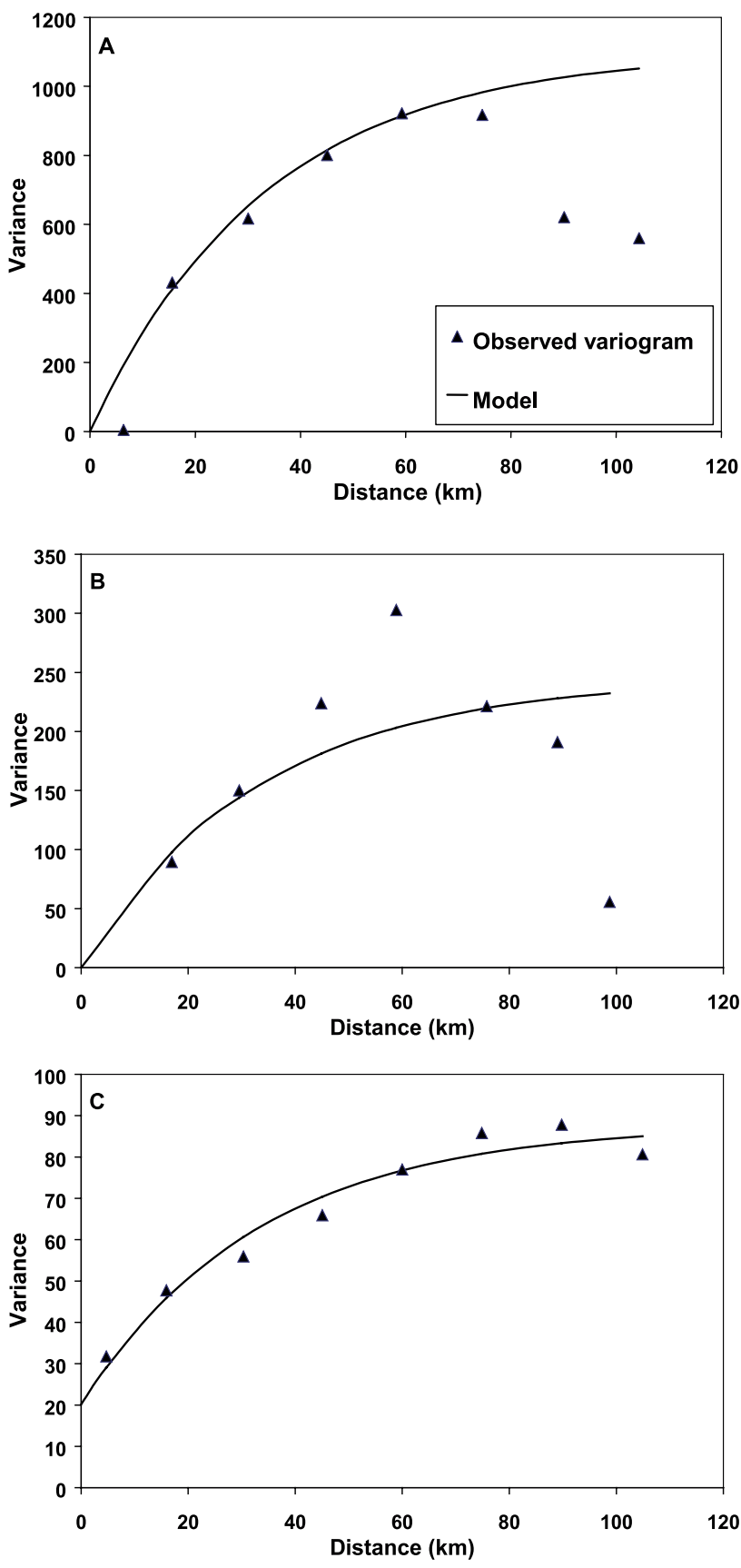

Figure 2. Simple and cross variograms for July 6, 1997 (day 187): (A) Botrytis; (B) Botrytis vs. relative humidity and (C) relative humidity.

of uncertainty $[6,7]$. A series of errors from various sources therefore accumulates during its estimation. Once again, the spatial structure of satellite relative humidity is characterized by rapidly increasing variance with a significant drop-off around $100 \mathrm{~km}$.

In the cross-variograms of the two variables (Fig. 2B), the structure of the spatial interdependence is less obvious, partic- ularly in the case of day 191 (for which the variograms are not presented here). This is attributable to the smaller number of points at which the two variables are observed simultaneously, namely eight in the case of this particular date. For day 187, the number of simultaneous observation points was higher (13), resulting in a more obvious spatial structure, especially at short distances (less than $50 \mathrm{~km}$ ).

The observed variograms were modelled particularly on the basis of the shape of the simple variograms. The model chosen was the exponential model [16] with a range of $100 \mathrm{~km}$. A nugget effect model was added in the case of satellite relative humidity in order to model the observed discontinuity at the origin.

This choice seems to describe the spatial structure of relative humidity very well (this variable is extensively sampled) and fairly well in the case of the primary variable (the sporulation index), particularly beyond a distance of $75 \mathrm{~km}$. It also yields an acceptable characterization of the spatial interdependence of the two variables if the fifth distance interval for day 187 is disregarded. Such outlying points could be the result of an inadequate number of pairs of observations.

The spatial structure models were employed for the estimation of the Botrytis sporulation index using kriging and cokriging at all points of the territory on the same grid as the satellite images. The estimation was performed using an optimal neighbourhood structure, which was determined using the results of the cross-validation applied iteratively until the neighbourhood structure that produced the best estimation was obtained. This was a search circle with a radius of $100 \mathrm{~km}$ divided into eight sectors with the optimal number of observations per sector set at two.

The same neighbour search strategy used for kriging and cokriging was employed, during the cross-validation, in the estimation of the sporulation index by the inverse distance method.

Table III provides descriptive statistics of the cross-validation results of the four interpolation methods for the Botrytis sporulation index as well as statistics on the distribution of the true values of the model outputs observed at the meteorological stations. These statistics demonstrate that all the interpolation methods exhibit a global bias. On average, the various interpolation techniques yielded estimates higher than the observed values. However, the nearest neighbour technique was the method which yielded estimates whose distribution was most similar to the observed values. The other methods produced less variable estimations (This is particularly evident from their lower coefficients of variation). The low estimation variability of the inverse distance, kriging or cokriging methods is known as smoothing. This is attributable to the nature of the estimation procedure, which consists in a linear combination of several observed values. The inverse distance method was the method most affected by the smoothing (lowest CV), while estimation by cokriging was the least affected. Since it uses the original values in the estimation, interpolation using the nearest neighbour method produced unsmoothed values.

Table III also shows that kriging and cokriging produced the lowest value for the standard deviation of the error as well as the least biased estimation with the lowest mean error values. This is in agreement with their primary objectives, namely obtaining an unbiased estimation while minimizing the estimation error. 
Table III. Results of the cross-validation of the four interpolation techniques for the leaf blight of onion model (Botrytis).

\begin{tabular}{|c|c|c|c|c|c|c|c|c|c|}
\hline \multirow{2}{*}{ Date } & & \multirow{2}{*}{$\mathrm{R}^{2^{b}}$} & \multicolumn{3}{|c|}{ Variable } & \multicolumn{4}{|c|}{ Error $^{a}$} \\
\hline & & & $\mathrm{m}^{c}$ & $\sigma^{d}$ & $\mathrm{CV}^{e}$ & $\mathrm{~m}^{c}$ & $\mathrm{MAE}^{f}$ & $\mathrm{RMSE}^{g}$ & $\sigma^{d}$ \\
\hline \multirow{5}{*}{$187-8: 00 \mathrm{am}$} & Observed values & - & 41.87 & 26.83 & 0.64 & - & - & - & - \\
\hline & Nearest neighbour & 0.30 & 43.17 & 28.25 & 0.65 & 1.30 & 19.85 & 25.67 & 26.14 \\
\hline & Inverse distance & 0.32 & 43.34 & 16.02 & 0.37 & 1.46 & 18.32 & 21.71 & 22.09 \\
\hline & Ordinary kriging & 0.48 & 42.84 & 17.03 & 0.40 & 0.96 & 16.49 & 19.09 & 19.44 \\
\hline & Cokriging & 0.50 & 43.26 & 22.97 & 0.53 & 0.94 & 16.14 & 19.37 & 19.74 \\
\hline \multirow{5}{*}{ 191-8:00 am } & Observed values & - & 27.72 & 20.96 & 0.76 & - & - & - & - \\
\hline & Nearest neighbour & 0.15 & 29.67 & 19.36 & 0.65 & 1.95 & 16.37 & 22.08 & 22.43 \\
\hline & Inverse distance & 0.19 & 29.55 & 10.88 & 0.37 & 1.84 & 15.50 & 18.65 & 18.92 \\
\hline & Ordinary kriging & 0.31 & 28.81 & 11.40 & 0.40 & 1.09 & 15.10 & 17.15 & 17.46 \\
\hline & Cokriging & 0.35 & 29.10 & 12.51 & 0.43 & 0.57 & 14.08 & 16.63 & 16.96 \\
\hline
\end{tabular}

${ }_{a}$ : Difference between the estimated value $\left(Z_{i}^{*}\right)$ and the observed value $\left(Z_{i}\right): e_{i}=Z_{i}^{*}-Z_{i}$;

$b^{b}$ : Coefficient of determination of the cross-validation;

$c$ : Mean value;

$d_{\text {: }}$ Standard deviation;

$e^{e}$ : Coefficient of variation;

$f:$ Mean absolute error: $M A E=\frac{1}{n} \sum_{i=1}^{n}\left|e_{i}\right|, n$ being the total number of points sampled;

g: Root mean square error: $R M S E=\sqrt[1]{\frac{1}{n} \sum_{i=1}^{n} e_{i}^{2} .}$

Cokriging was the most successful method for estimating the Botrytis sporulation index, according to several criteria. It had the lowest mean absolute error and root mean square error values as well as the narrowest distribution error (low standard deviation values). In addition, the coefficient of determination between the observed values and the estimated values was higher for cokriging than for all the other interpolation techniques studied. With respect to this parameter, cokriging yielded better results for day 187 than day 191. This could be explained by the fact that for the 187th Julian day, the number of simultaneous observation points of the primary and auxiliary variables as well as the amplitude of the relationship between them were greater, which better explained the spatial interdependence between the two variables in order to produce estimates closer to the observed values. For day 187, all the interpolation methods generally recorded better results, in terms of the coefficient of determination. This could be attributed to the greater variability of the Botrytis sporulation index on day 191 (the CV of day 191 was 0.76 , versus 0.64 for day 187 , Tab. III), making the neighbouring values less similar and consequently less appropriate for inclusion in the estimation.

Figure 3 presents the interpolation maps for the Botrytis sporulation index using kriging and cokriging. The estimation error maps were superimposed as isolines expressing the standard deviation of the estimation in terms of the sporulation index value. The initial visual impression is that estimation by kriging is smoother than by cokriging. The two methods were less successful in the extrapolation area (few or no meteorological stations), which extends from Trois-Rivières to Saint-Jovite and to the north and southwest of Saint-Jovite.
Here again, cokriging was more effective and yielded more accurate estimations than kriging. For both dates, in the case of cokriging, the isolines for a given level of standard deviation are located further from the meteorological stations than is the case for kriging. For example, isoline 20, which the kriging method placed north of the Montreal area, was pushed further to the north when cokriging was used. This denotes an improvement in the accuracy of the estimation. This comment is valid for the other isolines. However, the improvement was less pronounced on the map for day 191. This difference is attributed to the fact that on day 191, there were a lower number of simultaneous observations of the primary and auxiliary variable, and the observed relationship between them was also weaker. This made it difficult to accurately model the structure of the spatial interdependence between the two variables so that it could be used to improve the quality of the estimation. In addition, the satellite variable images for day 191 were characterized by larger cloud-covered areas [7]. Consequently, this limited the number of observation points of the auxiliary variable that could be used in the estimation.

In the case of cokriging, for both dates, the isoline representing an estimation error with a value of 10 units is located at a distance of $3 \mathrm{~km}$ from the stations (Fig. 3). This uncertainty value compared to the mean values of the index observed on day 187 and day 191 represents a mean relative error ${ }^{1}$ of 0.24 and 0.36 , respectively. These values are lower than those of the

\footnotetext{
${ }^{1}$ The mean relative error was calculated by dividing the value of the estimation error of the isoline by the mean value of the output of the corresponding date shown in Table III.
} 


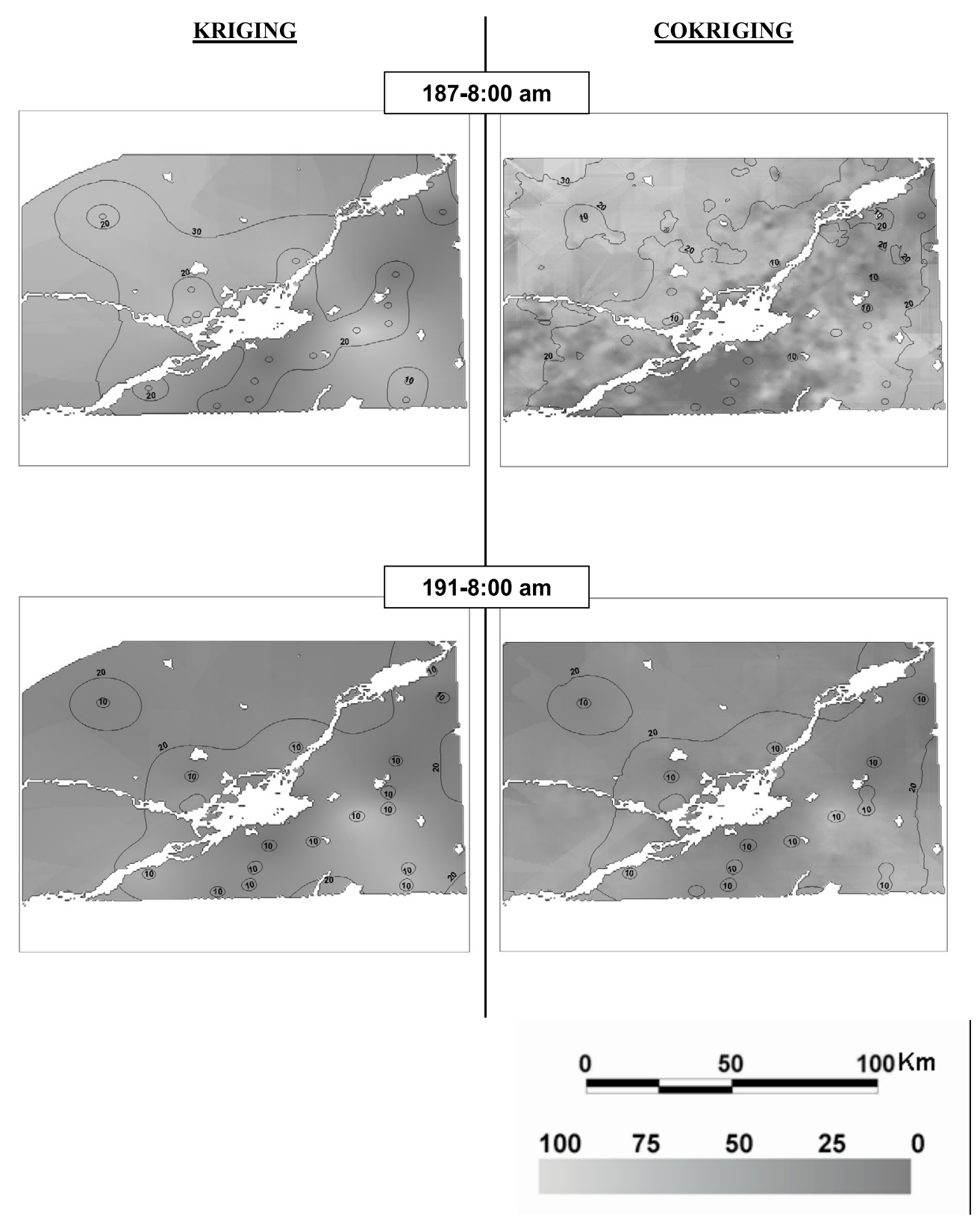

Figure 3. Maps of the sporulation index of leaf blight of onion and of the estimation error by kriging and cokriging.

global error caused by uncertainty on the model input variables, calculated at 0.53 and 0.94 , respectively [8].

The comment above concerning the estimation of the 191st Julian day which was less accurate than for the 187th day, because of the greater variability of the index on the first day, is confirmed in the interpolated map. In general and for both dates, the accuracy of the estimation in the study area was \pm 20 units of the sporulation index (Fig. 3). Given that the mean value of the estimated sporulation index was approximately 43 on day 187 and 29 on day 191 (Tab. III), this inaccuracy thus represents a fairly high level of estimation variation relative to the estimated value.
However, the interpolated maps of the Botrytis sporulation index show a structure in the configuration of the spatial distribution of the index. For both dates, Montérégie-West (region bounded to the north by the greater Montreal area, to the west by the St. Lawrence River and to the east by the Richelieu River) was characterized by a low sporulation index, often less than 40. The same index range was also observed in the area extending from Saint-Zéphirin to Saint-Hyacinthe and including Saint-Simon. However, high sporulation index values (higher than 40) were recorded in the Lower Laurentians and Lanaudière around the L'Assomption and Mirabel stations, in the area located between the Ottawa River and the St. Lawrence 
River (to the southwest of the greater Montreal area, to the north of the Saint-Anicet station) and also in Montérégie-East, particularly the area located between the Rougement, Stukely and Frelighsburg stations (Fig. 3).

\subsection{Carrot weevil models}

By comparing the accumulated degree days as calculated by the model to the satellite temperature values, it was found that on June 5, 1997 (156th Julian day), the relationship between the primary variable and the auxiliary variable was the strongest, with a coefficient of determination of 0.67 . This day differs from the other two (June 3 and 8, 1997, respectively, the 154th and 159th Julian day) by weaker cloud cover, thus ensuring the maximum number of simultaneous observation points of the model outputs and of the satellite temperature (15 observation points) [6]. On the 154th Julian day, the relationship between the primary variable and the auxiliary variable was weaker (coefficient of determination of 0.31 for day 154, versus 0.51 for day 159), even though the number of observations was comparable to day 159 (11 observation points for day 154 and 10 points for day 159). In fact, for this date, the satellite temperature calculated above the study area was generally lower than for the other two dates $[6,7]$, reflecting the cooler weather conditions, resulting in a lower contribution of this day to the accumulation of degree days by the model.

In order to study the spatial structure of the outputs of the carrot weevil model, the spatial structure of the satellite temperature as well as their spatial interdependence, the simple and cross omnidirectional covariograms were calculated using a distance interval of $20 \mathrm{~km}$ and a distance tolerance of $50 \%$ (Fig. 4). The covariogram expresses, as a function of distance, the covariance between the pairs of observations separated by a multiple of the distance interval. For a regionalized variable, the covariance decreases as a function of the distance before levelling off. Theoretically, past the distance (the range) at which this levelling-off occurs, there is no longer any spatial correlation between the pairs of observations.

The use of a covariogram instead of a variogram was dictated by the spatial structure of the variables. In this case, the covariogram proved to be more appropriate, for various reasons. At the outset, it appears that the range of the spatial structure is low and is close to the origin (Fig. 4), which means that the spatial correlation occurs at short distances. With a distance interval of $20 \mathrm{~km}$, the variogram did not make it possible to adequately describe the spatial structure of the accumulated degree days according to the two models, particularly since the first point of the variogram calculated is at a distance of about $20 \mathrm{~km}$. Furthermore, the variogram does not give any value of the variance at the origin. It models the spatial structure at short distances and is estimated by extrapolating the variance values of the other points around the origin, which is easy to do when the spatial structure at short distances is fairly obvious. In the opposite case, the covariogram is more appropriate, particularly since it estimates the covariance at the origin.

The choice of the distance interval involved a delicate compromise between the statistical robustness of the calculated values of the structure function, assured by a large distance interval, which therefore included a sufficient number of pairs of observations, and the goal of determining the spatial struc- ture at short distances by using smaller distance intervals. It should be pointed out that the covariogram is composed of two parts, theoretically symmetrical, based on the direction of the distance vector: one positive and the other negative. Here, only the positive parts of the simple and cross covariograms are presented. According to the observed simple covariograms (Fig. 4A), the spatial variability of the accumulated degree days according to the model has a structure characterized by a quasi linear decrease in the covariance, levelling off around the second distance interval and a second linear decrease phase past $70 \mathrm{~km}$. The first two parts of the covariogram denote the existence of a spatial autocorrelation in the model outputs that could be modelled and then used in their regionalization. The last part of the covariogram, for its part, could indicate the existence of a trend in the data past $70 \mathrm{~km}$. The existence of such a trend is contrary to the basic geostatistic hypothesis of stationarity [5, 16]. Which points out the existence of a subgroup in the weather stations located in the periphery of the studied territory that is statistically different from the rest of the sample. In fact, stations such as Saint-Jovite or Trois-Rivières, because of their elevation or latitude, appear to belong to different climatological zones than the rest of the weather stations. This trend could be incorporated in the geostatistical analysis by estimating it by means of a regression model. Once estimated, the trend is eliminated from the data and the analysis is then performed on the presumed stationary residuals. However, since the observed covariograms of the outputs of the model reaches its sill at a shorter distance than that at which the trend in the data appears, this trend was disregarded and only the first part of the covariogram was considered.

The auxiliary variable, namely satellite air temperature, exhibited a spatial variability structure similar to that of the accumulated degree days, at least for the first $70 \mathrm{~km}$ (Fig. 4C). It should be noted that there is no drift in the satellite temperature data. In fact, this temperature is a regionalized variable describing the atmospheric weather conditions. Since these conditions, at the spatial scale of the study, are subject to the mechanisms of mixing and stirring, they do not necessarily reflect the climatological characteristics of the region. However, since degree days are an accumulation of temperature over the course of the season, they increasingly reflect the climatological characteristics of the region, which causes them to deviate increasingly from the regionalized variables and leads to the emergence of trends within these data.

With the exception of those for day 154, the observed cross covariograms between the accumulated degree days and satellite temperature exhibit a spatial interdependence structure comparable to those of the simple covariograms of the model outputs (Fig. 4B). This means that the two variables progress spatially in the same direction; in other words, high satellite air temperature values are observed alongside high degree day values and vice versa. The anomaly of day 154 is attributable to the weak correlation observed between the satellite variable and the outputs of the two models. This made it impossible to measure and describe the joint spatial variability structure of the two variables on this date. The trend effect past $70 \mathrm{~km}$ was less evident in the cross covariograms.

A spherical model with a range of $30 \mathrm{~km}$ was fitted to all of the simple and cross corvariograms. This choice was justified by the structure of the covariograms marked by a quasi linear 

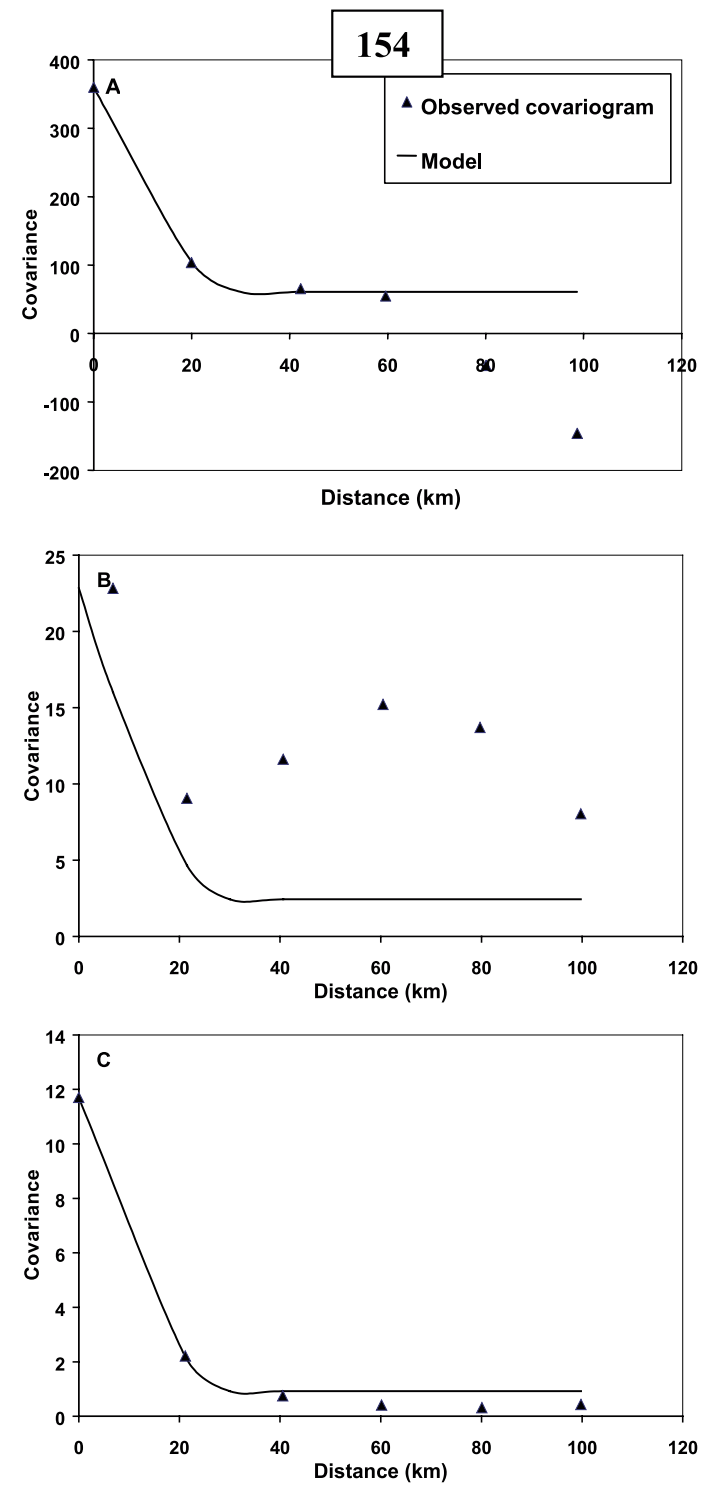

156
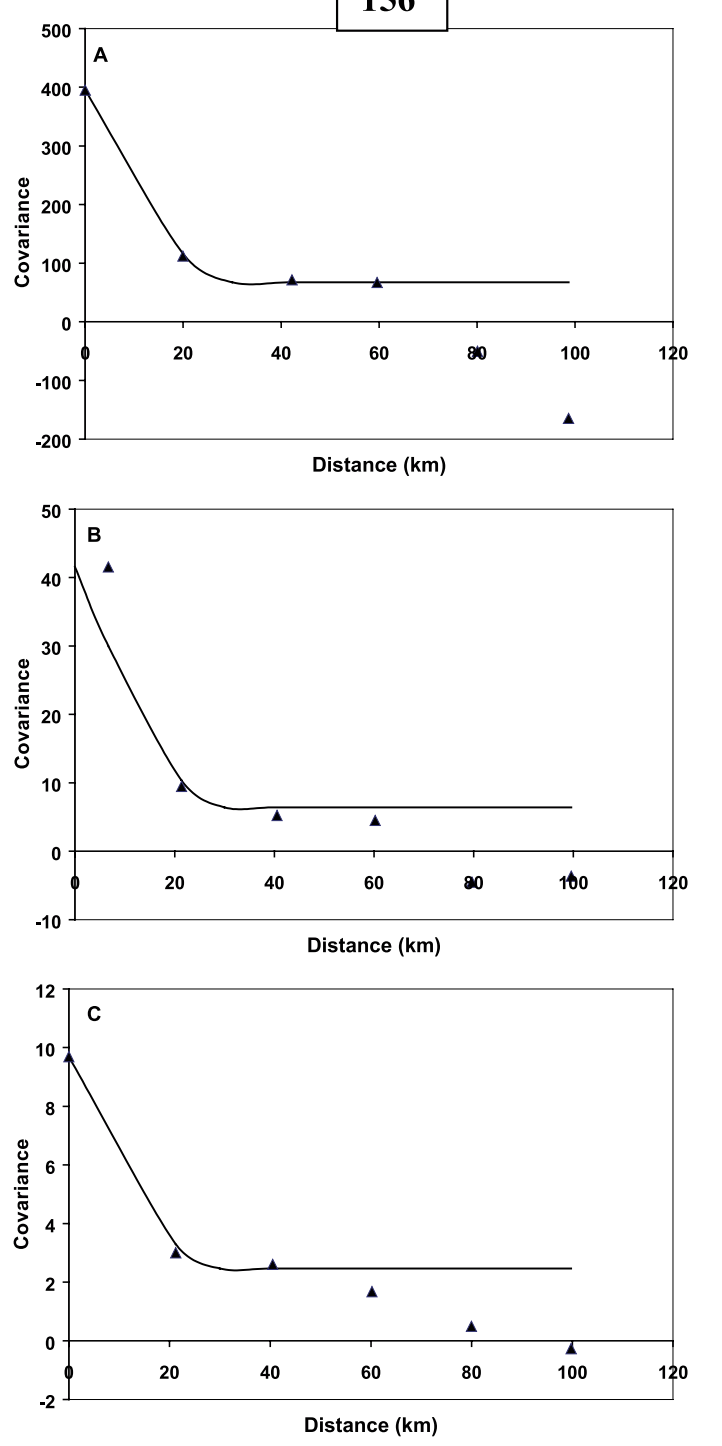

159
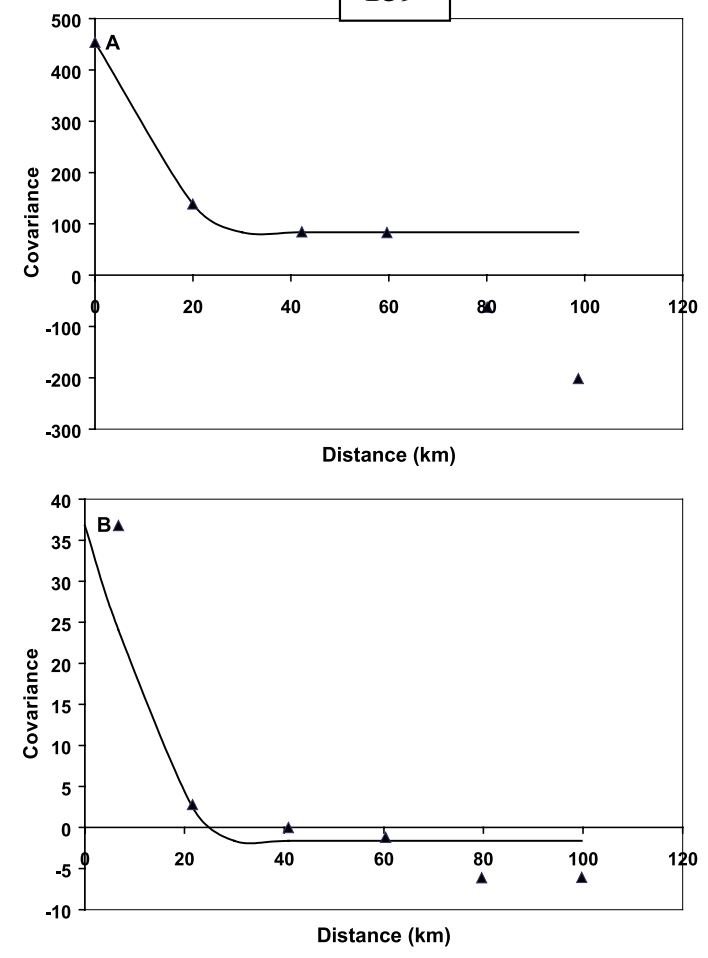

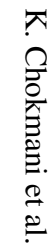

Figure 4. Simple and cross omnidirectional covariograms: (A) weevil; (B) weevil vs. temperature and (C) temperature.

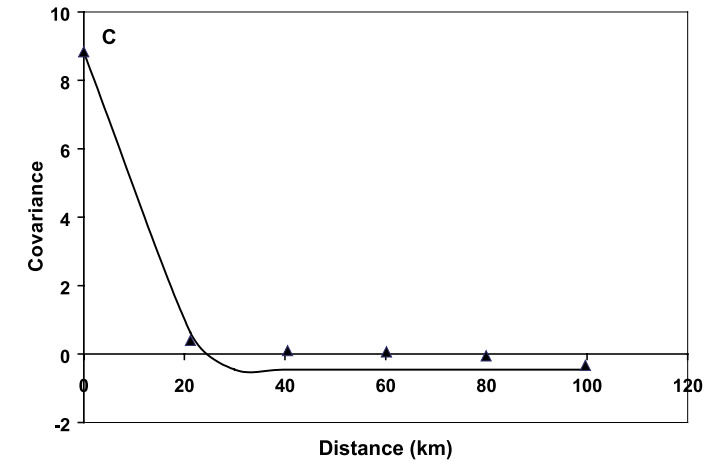


Table IV. Results of the cross-validation of the four interpolation techniques for the carrot weevil model.

\begin{tabular}{|c|c|c|c|c|c|c|c|c|c|}
\hline \multirow{2}{*}{ Date } & & \multirow{2}{*}{$\mathrm{R}^{2^{b}}$} & \multicolumn{3}{|c|}{ Variable } & \multicolumn{4}{|c|}{ Error $^{a}$} \\
\hline & & & $\mathrm{m}$ & $\sigma$ & $\mathrm{CV}$ & $\mathrm{m}^{c}$ & $\mathrm{MAE}^{f}$ & $\mathrm{RMSE}^{g}$ & $\sigma^{d}$ \\
\hline \multirow{5}{*}{154} & Observed values & - & 186.30 & 19.35 & 0.10 & - & - & - & - \\
\hline & Nearest neighbour & 0.35 & 191.28 & 13.45 & 0.07 & 4.98 & 14.48 & 16.22 & 15.75 \\
\hline & Inverse distance & 0.32 & 190.04 & 11.36 & 0.06 & 2.42 & 12.38 & 15.20 & 15.32 \\
\hline & Ordinary kriging & 0.30 & 189.53 & 11.07 & 0.06 & 1.91 & 12.50 & 15.31 & 15.51 \\
\hline & Cokriging & 0.35 & 190.17 & 12.15 & 0.06 & 2.21 & 11.89 & 14.32 & 14.44 \\
\hline \multirow{5}{*}{156} & Observed values & - & 203.18 & 20.27 & 0.10 & - & - & - & - \\
\hline & Nearest neighbour & 0.31 & 208.48 & 14.06 & 0.07 & 5.30 & 15.70 & 17.54 & 17.05 \\
\hline & Inverse distance & 0.31 & 207.17 & 11.90 & 0.06 & 2.58 & 13.41 & 16.04 & 16.15 \\
\hline & Ordinary kriging & 0.31 & 206.62 & 11.72 & 0.06 & 2.03 & 13.30 & 15.96 & 16.16 \\
\hline & Cokriging & 0.50 & 207.19 & 16.43 & 0.08 & 2.28 & 11.02 & 13.53 & 13.62 \\
\hline \multirow{5}{*}{159} & Observed values & - & 234.62 & 21.73 & 0.09 & - & - & - & - \\
\hline & Nearest neighbour & 0.32 & 240.20 & 15.29 & 0.06 & 5.58 & 16.64 & 18.74 & 18.24 \\
\hline & Inverse distance & 0.33 & 238.85 & 13.04 & 0.05 & 2.73 & 14.34 & 16.90 & 17.03 \\
\hline & Ordinary kriging & 0.35 & 238.33 & 12.84 & 0.05 & 2.20 & 13.96 & 16.54 & 16.73 \\
\hline & Cokriging & 0.40 & 237.59 & 16.16 & 0.07 & 1.21 & 13.98 & 15.81 & 16.09 \\
\hline
\end{tabular}

${ }_{a}$ : Difference between the estimated value $\left(Z_{i}^{*}\right)$ and the observed value $\left(Z_{i}\right): e_{i}=Z_{i}^{*}-Z_{i}$;

$b$ : Coefficient of determination of the cross-validation;

$c$ : Mean value;

$d_{\text {: Standard deviation; }}$

$e$ : Coefficient of variation;

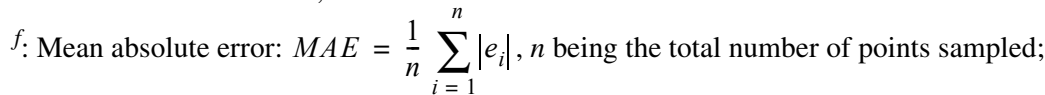

${ }^{g}:$ Root mean square error: $R M S E=\sqrt{\frac{1}{n} \sum_{i=1}^{n} e_{i}^{2}}$.

rapid decline phase of the spatial correlation, following which the covariance quickly stabilizes. During the fitting, the last part of the covariograms (past $70 \mathrm{~km}$ ) was disregarded in order to exclude the trend structure in the calculation of the model parameters.

The same optimal neighbourhood structure used for the Botrytis sporulation index was applied for the accumulated degree days according to the insect model in the cross-validation of the inverse distance, kriging and cokriging methods as well as for the estimation of the model outputs using the last two interpolation methods. This structure was a search circle divided into eight sectors with an optimal number of two observations per sector. However, the neighbour search radius was reduced in this case to $70 \mathrm{~km}$.

Table IV provides descriptive statistics on the results of the cross-validation of the four interpolation methods for the outputs of the weevil model as well as statistics on the distribution of the true values of the model outputs observed at the weather stations. The same comments made concerning the results of the cross-validation of the four interpolation methods applied to the Botrytis sporulation index are valid here, as confirmed by the outputs of the insect model. The four interpolation methods slightly overestimate the values of the accumulated degree days as calculated by the weevil model. The nearest neighbour technique was the method whose distribution of the estimation was most similar to the observed values. The results of the other methods were affected by smoothing. With respect to the coefficient of variation values, smoothing was most evident in the inverse distance technique and least evident in cokriging.

Here again, the distribution of the error of the various interpolation methods (Tab. IV) shows that the two geostatistical techniques achieved their estimation objectives by minimizing the estimation bias and error. They produced the lowest mean and standard deviation of the error values. On the other hand, the nearest neighbour technique produced the most biased estimation, with the highest mean error value.

Also, for all the dates, cokriging provided an estimation of the degree days with the lowest MAE and RMSE values and, especially, the highest values of the coefficient of determination between the observed and estimated values. This means that cokriging was successful in producing more accurate estimations of the degree days which, furthermore, compared to the other methods, were most similar to the observed values, making this the most accurate of the various interpolation techniques 


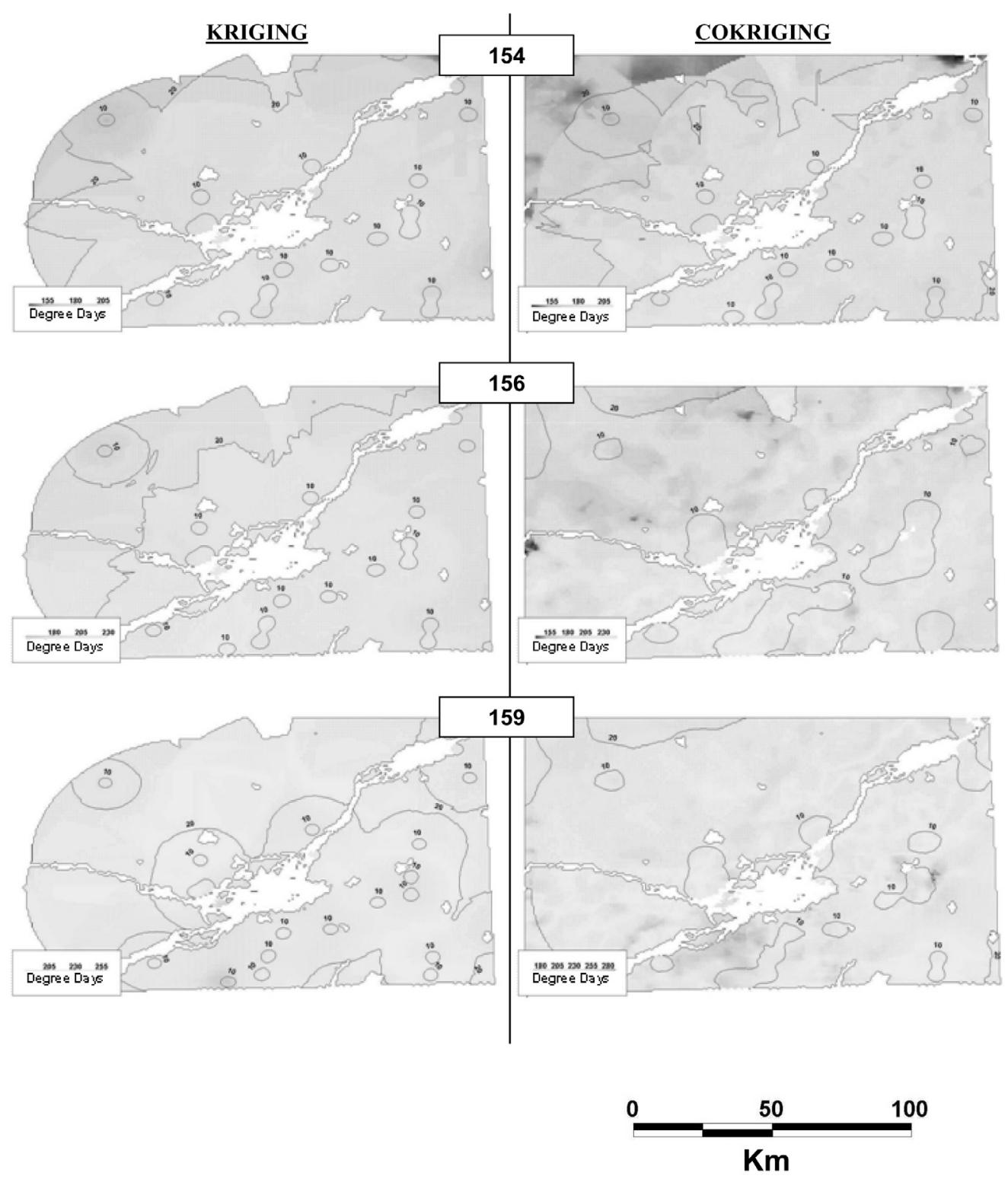

Figure 5. Maps of the accumulated degree days as calculated by the carrot weevil model interpolated using kriging and cokriging as well as of the estimation error.

studied. This superior performance was particularly evident for the 156th Julian day, when the number of simultaneous observations of the primary variable and the auxiliary variable as well as the degree of their relationship were the greatest.

The interpolation results using kriging and cokriging of the accumulated degree days according to the carrot weevil model are presented in Figure 5. The estimation error maps for the two techniques were superimposed on their interpolation maps in the form of isolines expressing the standard deviation of the estimation in degree day values.

As expected, the estimation of the accumulated degree days as calculated by the model using kriging was smoother than the estimation produced with cokriging. In addition, both methods yielded lower quality estimates in the northern and northeastern part of the territory under study, where there are few or no weather stations. Since the neighbour search radius was smaller than the radius used for the Botrytis model, because of an insufficient number of observations in the neighbourhood, kriging of the degree days did not produce an estimation in part of this area. However, since a sufficient number of observations of the satellite variable in this region was available, cokriging was able to provide estimations for this region.

For the interpolation of the accumulated degree days according to the insect model, cokriging using satellite air temperature was generally more effective and produced more accurate estimations than kriging. The level of accuracy achieved was 
directly related to the intensity of the relationship between the primary variable and the auxiliary variable as well as to the number of simultaneous observations of these variables. For the 156th Julian day, for example, where the relationship between degree days and satellite temperature was strongest and the number of simultaneous observation points highest, the isolines for a given level of error were much further from the weather stations in the case of cokriging than they were in the maps interpolated by kriging. The superior performance of cokriging was less evident for the 159th Julian day, when the relationship between the primary variable and the auxiliary variable was weaker.

The relationship observed between the primary variable and the auxiliary variable was weakest for day 154 . For this day, cokriging yielded virtually no improvement in the quality of the estimation compared to kriging (Fig. 5). This is due to the fact that the spatial interdependence model was unable to measure the true spatial correlation between the primary and auxiliary variables (Fig. 4B).

Figure 5 shows the structure of the spatial distribution of the accumulated degree days as calculated by the carrot weevil model. On the south shore of the St. Lawrence River (Montérégie-East and West) and all the areas adjoining the greater Montreal area, degree days were accumulated at a faster rate than on the north shore of the St. Lawrence River and of the Ottawa River (Lower Laurentians and south of Lanaudière). This configuration is dictated by a combination of several factors: the north-south temperature gradient on the one hand, the island of warming effect generated by the greater Montreal area and the elevation gradient between the areas at higher elevations (Laurentians to the north and Appalachians to the south) and the St. Lawrence Valley and its tributaries on the other hand.

\section{CONCLUSIONS}

In this study, the relationship observed between the outputs of two crop protection models and the satellite variables was used to regionalize their outputs and produce maps by applying the cokriging method. The results were validated using the cross-validation technique, compared to the results obtained by ordinary kriging and by two conventional interpolation methods, namely the nearest neighbour method and the inverse distance weighted average method.

The results were unambiguous. In fact, for the two crop protection models studied and for all the dates, cokriging using satellite variables demonstrated its superiority in the interpolation of the model outputs, compared to the other techniques, in several respects: the low level of bias and smoothing in the estimation by cokriging, the greater similarity of the cokriging results to the observed values (higher coefficient of determination values) and the lowest distribution of error (lower $M A E$ and $R M S E$ values). In addition, by using cokriging, it was possible to produce maps of the model outputs with greater spatial accuracy than with kriging. The two conventional techniques were quite simply incapable of calculating the accuracy of the estimation. In the case where the neighbour search radius was not sufficient to cover the entire territory, cokriging made it possible to take advantage of the auxiliary variable to produce estimations covering the entire territory under study.
The degree of success of cokriging was directly related to the intensity of the relationship observed between the primary variable and the auxiliary variable as well as to the number of simultaneous observations of these variables. A strong relationship between the two variables combined with a sufficient number of simultaneous observation points made it possible to clearly identify and more accurately measure the spatial interdependence between the two variables. It was therefore possible to derive the maximum information from the spatial variability of the auxiliary variable, more extensively sampled, in order to predict the values of the primary variable at any point in the territory.

The greatest limitation in the application of cokriging for the interpolation of the outputs of the plant protection models using satellite variables was the presence of clouds above the territory under study. The extent of the cloud-free area and/or the persistence of remaining clouds affected cokriging performance. The extent of the satellite variable affected the number of simultaneous observations as well as the quality of the relationship between the primary variable and the auxiliary variable. However, it is possible to compensate for the limitations to the application of cokriging due to the presence of clouds by using images produced by weather forecasting models. These images could replace the satellite variables for the regions masked by clouds. Using the outputs of the forecasting models as supporting variables is a promising avenue that would make it possible to add the temporal dimension to the regionalization methodology developed in this study.

The analysis of the spatial structure showed that the autocorrelation in accumulated degree days was observed at a scale of less than $30 \mathrm{~km}$. Yet, only $25 \%$ of the 26 stations used are located less than $45 \mathrm{~km}$ from each other. Consequently, a larger number of stations would make possible more accurate measurement and description of the spatial structure of the variables, at a shorter scale. In the case of cokriging, this will improve the chances of obtaining simultaneous observations of the primary and auxiliary variables in order to clearly ascertain the structure of the spatial interdependence of the two types of variables.

Hence, we were able to develop an optimal methodology for regionalization of the outputs of the crop protection models which incorporates the spatial dimension in the forecasting models while taking into consideration the spatial variability of the environmental variables that govern pest development. Remote sensing offers an excellent source of information on the spatial variability of these variables that the meteorological network in its current configuration cannot provide.

Integrating the spatial dimension into crop protection in this manner represents a significant added value for crop protection managers, first of all by producing accurate infection risk maps, where the information is more representative of conditions in the field, which makes it possible to provide more accurate diagnoses based on the pest development indices, and secondly, the use of risk maps provides a regional overview of pest development and a better understanding of the characteristics of their spatial structure. This helps more effectively target and plan pest monitoring activities and various pest control actions.

Acknowledgements: We would like to thank the Geomatics Research Centre, Laval University, Agriculture and Agri-Food Canada's Horticulture Research and Development Centre in Saint-Jean-sur-Richelieu, as well as Environment Canada's 
Atmospheric Environment Service (AES) for their logistical and technical support. We would also like to thank the following funding agencies for their financial support: Conseil des Recherches en Pêche et en Agro-alimentaire du Québec (CORPAQ), Atmospheric Environment Service (AES), Natural Sciences and Engineering Research Council of Canada (NSERC) and Laval University's Geomatics Research Centre for their financial support. Contribution \#335/ 2004.09.05R of Agriculture and Agri-Food Canada.

\section{REFERENCES}

[1] Bourgeois G., Carisse O., Implantation et utilisation, en temps réel, de modèles prévisionnels d'infections phytopathogènes dans les cultures maraîchères et fruitières, Colloque international sur la prévision et le dépistage des ennemis des cultures, Québec, Canada, 1996, pp. 121-125.

[2] Bourgeois G., Plouffe D., Beaudry N., Chouinard G., Audet R., Deaudelin G., CIPRA: Computer Centre fro Agricultural Pest Forecasting. Agriculture and Agri-Food Canada, Saint-Jean-surRichelieu, Québec, Canada, Sainte-Foy, Québec, Canada, 19942004.

[3] Brewster C.C., Allen J.C., Kopp D.D., IPM from space: using satellite imagery to construct regional crop maps for studying crop-insect interaction, Am. Entomol. 45 (1999) 1912-1913.

[4] Campbell C.L., Madden L.V., Introduction to plant disease epidemiology, Wiley, New York, 1990.

[5] Chauvet P., Aide-mémoire de géostatistique linéaire, Les Presses, Écoles des Mines de Paris, Paris, 1999, 367 p.

[6] Chokmani K., Développement d'une méthodologie de régionalisation de quatre modèles de phytoprotection à l'aide des images NOAAAVHRR et d'outils géostatistiques. Département des Sciences Géomatique, Université Laval, Québec, Canada, 2002.

[7] Chokmani K., Viau A.A., Estimation de la température de l'air et de la quantité de la vapeur d'eau atmosphérique à l'aide des données AVHRR de NOAA, J. Can. Télédétect. (2004) (reviewed).

[8] Chokmani K., Viau A.A., Bourgeois G., Analyse de l'incertitude de quatre modèles de phytoprotection relative à l'erreur des mesures des variables agrométéorologiques d'entrée, Agronomie 21 (2001) 147-167.

[9] Chouinard G., Vincent C., Tartier L., Laplante G., Morin Y., Outils de dépistage et de prévision pour les insectes, acariens et maladies des vergers de pommiers du Québec, Colloque international sur la prévision et le dépistage des ennemis des cultures, Québec, Canada, 1996, pp. 163-184.

[10] Cracknell A.P., The Advanced Very High Resolution Radiometer (AVHRR), Taylor \& Francis Londre Ltd, Londre, 1997, 534 p.

[11] Dungan J., Spatial prediction of vegetation quantities using ground and image data, Int. J. Remote Sens. 19 (1998) 267-285.

[12] Fleischer S.J., Blom P.E., Weisz R., Sampling in precision IPM: When the objective is a map, Phytopathology 89 (1999) 1112 1118.
[13] Fotheringham A.S., Brunsdon C., Charlton M., Quantitative geography: Perspectives on spatial data analysis, SAGE Publications, London, UK, 2000, 270 p.

[14] Gleason M.L., Taylor S.E., Loughin T.M., Koehler K.J., Development and validation of an empirical model to estimate the duration of dew periods, Plant Dis. 78 (1994) 1011-1016.

[15] Hatfield J.L., Pinter P.J.J., Remote sensing for crop protection, Crop Prot. 12 (1993) 403-413.

[16] Isaaks E.H., Srivistava R.M., Applied geostatistics, Oxford University Press, New York, 1989, 561 p.

[17] Kranz J., Measuring plant disease, in: Kranz J., Rotem J. (Eds.), Experimental techniques in plant disease epidemiology, SpringerVerlag, Berlin, 1988, pp. 35-50.

[18] Lam N.S.N., Spatial interpolation Methods: A review, Am. Cartograph. 10 (1983) 129-149.

[19] Legendre P., Spatial autocorrelation: trouble or new paradigm? Ecology 74 (1993) 1659-1673.

[20] Legendre P., Fortin M., Spatial pattern and ecological analysis, Vegetatio 80 (1989) 107-138.

[21] Margueret V., Analyse spatiale : techniques et applicabilité pour la distribution de deux essences forestières à la forêt Duchesnay, Université Laval, Québec, Canada, 2000, p. 100.

[22] Nilsson H.E., Remote sensing and image analysis in plant pathology, Ann. Rev. Phytopathol. 33 (1995) 489-527.

[23] Paquet F., Détermination de zones agrométéorologiques homogènes par l'intégration de données météorologiques satellitaires et physiographiques, Université Laval, Québec, Canada, 1996.

[24] Prince S.D., Goward S.N., Global primary production: a remote sensing approach, J. Biogeogr. 22 (1995) 815-835

[25] Real L.A., McElhany P., Spatial pattern and process in plantpathogen interactions, Ecology 77 (1996) 1011-1025.

[26] Rossi R.E., Mulla D.J., Journel A.G., Franz E.H., Geostatistical tools for modeling and interpreting ecological spatial dependence, Ecolog. Monogr. 62 (1992) 277-314

[27] Shaw M.W., Modelling stochastic processes in plant pathology, Annu. Rev. Phytopathol. 32 (1994) 523-544.

[28] Viau A.A., Optimisation et régionalisation des réseaux climatologiques à l'aide d'outils géomatiques, Publ. Assoc. Int. Climatol. 9 (1997) 262-272.

[29] Vogt J., Viau A.A., Paquet F., Mapping regional air temperature fields using satellite derived surface skin temperatures, Int. J. Climatol. 17 (1997) 1559-1579.

[30] Weseloh R.M., Developing and validating a model for predicting Gypsy Moth (Lepidoptera: Lymantriidae) defoliation in Connecticut, J. Econ. Entomol. 89 (1996) 1546-1555.

[31] Zadoks J.C., Bosch F.V.d., On the spread of plant disease: a theory on foci, Annu. Rev. Phytopathol. 32 (1994) 503-521. 